\title{
Behaviour of Reinforcement in RCC Structure when Subjected to Fire
}

\author{
Ashish Juneja ${ }^{1}$, Rajinder Singh ${ }^{2}$ \\ ${ }^{1}$ Student, Department of Civil Engineering, R.N. College of Engineering (Panipat) \\ ${ }^{2}$ Assistant Professor, Department of Civil Engineering, R.N. College of Engineering (Panipat)
}

\begin{abstract}
As we all aware that hazards of major fires and fire mishaps are increasing day by day in structures. Therefore evaluation, rehabilitation and repair of structures damaged by fire have become a newsworthy. Effect of fire is most serious potential risk to most of RCC STRUCTURE. In today's world concrete is most widely used in construction field. So, for researchers to make concrete fire resistant has become tropical interest. In many country's several researchers did researches on this topic. In this area Research and developmental efforts are continuously being carried out and other disciplines are also trying to research on this topic.The reality of actual life issue are expressed which gives us real feeling in this topic. From this research we would be familiar on the absolute approach for the rehabilitation of structure damaged due to fire. Also express a particular evaluation and procedures by conducting some techniques known as NDT, and recovering method. To find out the effect of the fire on reinforcement steel bars we performed some experiment on 6 samples, each bar heated to $150^{\circ}, 350^{\circ}, 650^{\circ}, 950^{\circ}$ centigrade temperature. After heating all samples are rapidly cooled in water by quenching and under air cooling also by normal process. Observed properties of samples changed(mechanical) by using universal testing machine (UTM) and grain size and grain structure is studied by scanning electron microscope (SEM) that is known as microscopic study. We conclude that more than half of $\mathrm{RC}$ structures are restorable which are damaged due to fire. As the temperature increases mechanical properties of material decreases. Analysis of structure in fire conditions is done by testing the properties of the composing materials, steel and concrete, at elevated temperature. By the effects of heating, steel and concrete have certain change in their strength, physical properties, and stiffness and some are repairable and some not after consequent cooling. The reinforcement bars when exposed to elevated temperature above $950^{\circ} \mathrm{C}$ was observed that ductility reduced when rapidly cooled by water. The bar which is cooled under normal atmospheric conditions the impact of temperature on ductility is not high. Mechanical properties can be altered without changing the chemical constituent by heating the reinforcement bars.
\end{abstract}

Keywords: Reinforcement, heat, ductility, tensile, strength.

\section{Introduction}

We are all aware of the damage that fire can cause in terms of loss of life, homes and livelihoods. A study of 15 industrialized nations (12 in Europe plus the Canada, USA, and Japan) found that, in a typical year, the number of people killed by fires was 1.1 to 2.5 per 100,000 inhabitants and the total cost of fire damage amounted to $0.25 \%$ to $0.35 \%$ of GNP. In the USA specifically, statistics collected by the National Fire Protection Association (USA) for the year 3000 showed that more than 5,000 deaths, over 100,000 injuries and more than $\$ 12 \mathrm{bn}$ of property damage were caused by fire. UK statistics suggest that of the half a million fires per annum attended by firefighters, about two third occur in occupied buildings and these result in around 700 fatalities (almost all of which happen in dwellings). The loss of business resulting from fires in commercial and office buildings runs into millions of pounds each year. The extent of such damage depends on a number of factors such as building design and use, structural performance, fire extinguishing devices and evacuation procedures. Although fire safety standards are written with this express purpose, it is understandably the safety of people that assumes the greater importance. Appropriate design and choice of materials is crucial in ensuring fire safe construction. Codes and regulations on fire safety are updated continually, usually as a result of research and development.

\subsection{Properties of concrete structure under fire}

Concrete is said to have a high degree of fire resistance and, in the majority of applications, concrete can be described as virtually 'fireproof'. We can examine extent of heat through textural appearance of structural members

\section{A) Condition of plaster and finish}

The condition of these finishes is categorized and recorded into five groups; unaffected, peeling, substantial loss, total loss and destroyed.

\section{B) Color}

Due to fire discoloration takes place and the possible change in concrete is normal, pink, whitish grey and puff.

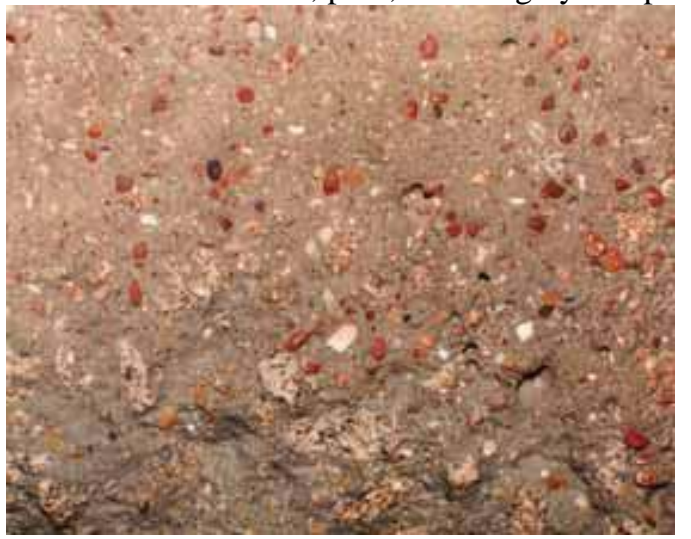

Figure 1.1: Color change in the concrete due to elevated temperature 


\subsection{List of tests to be conducted}

\subsubsection{Non destructive In situ field testing}

1) Ultrasonic Pulse Test (UPV):

2) Schmid hammer test

3) Core test

\subsubsection{Laboratory Tests}

4) Thermo gravimetric Analysis (TGA)

5) Differential Thermal Analysis (DTA)

6) X-Ray Diffraction (XRD)

\subsection{Objective}

The present work includes

1) To study the impact of fire on the reinforcement bars heated at various temperatures, cooled rapidly by quenching in water and normalized by cooling in the atmospheric temperature.

2) Study the characteristic changes in the mechanical properties of the bars by Tensile strength testing using Universal Testing Machine.

3) Study of micro structure of the bars using Scanning Electron Microscope (SEM).

\section{Literature Review}

Ian A.FLETCHER, Stephen WELCH, José L. TORERO, Richard O. CARVEL, Asif USMANI

The performance of steel during a fire is understood to a higher degree than the performance of concrete, and the strength of steel at a given temperature can be predicted with reasonable confidence.

\section{Conclusion:}

Higher temperatures will result in significant expansion of the steel compared to the concrete and, if temperatures of the order of $700^{\circ} \mathrm{C}$ are attained, the load-bearing capacity of the steel reinforcement will be reduced to about $20 \%$ of its design value

Riley,Msc. Possible new method for the assessment of fire-damaged structures. Sir william halcrow and partners- 1991

The bond behavior between fiber reinforced concrete and 20$\mathrm{mm}$ reinforcing steel rebar was evaluated under elevated temperatures.

\section{Conclusion:}

Use of fibers minimized the damage in steel-concrete bond under elevated temperatures and hence the reduction in bond strength.
3.2 UTM

A machine is used to test specimens for tensile strength, compressive strength, shear strength and to perform bend test along other important laboratory tests.

The aim of the test is to assess some mechanical characteristics of testing material: its elasticity, ductility, resilience and toughness.

\subsection{SEM}

Scanning Electron Microscopy has done by JSM- 6480LV at magnification of 5 microns (x5000) and 10 microns (x1000).

\subsection{Electrical Furnace}

The electric furnace is used to heat the specimens. The maximum temperature attained in this furnace is $1000^{\circ} \mathrm{C}$.

The 3 specimens which are quenched in water are removed after 15 minutes. Each time 6 bars are kept at temperatures of $100^{\circ} \mathrm{C}, 300^{\circ} \mathrm{C}, 600^{\circ} \mathrm{C}, 900^{\circ} \mathrm{C}$ and the same is repeated.

\subsection{Testing}

The specimens of Kamdhenu TMT bar of $12 \mathrm{~mm}$ diameter were taken for testing. 52 bars were cut to $42 \mathrm{~cm}$ size. 8 samples were tried to find the mechanical properties using UTM, when warming during typical temperature and the properties were tabulated.10 specimens each were heated in the electrical furnace at $150^{\circ}, 350^{\circ}, 650^{\circ}$ and $950^{\circ} \mathrm{C}$ for approx $60 \mathrm{~min}$ without any interference. When heating process completed, for each temperature, 6 samples were quenched in water out of 10 specimens, for rapid cooling and the remaining 6 were allowed for normal cooling at atmospheric temperature. These samples after the fact were tried to find mechanical properties by using UTM Furthermore microstructure investigation utilizing SEM.

\section{Results and Discussions}

\subsection{Results from computerized UTM}

Table 1: Margin specifications

\begin{tabular}{|c|c|c|c|c|c|}
\hline $\begin{array}{c}\text { Sr. } \\
\text { No. }\end{array}$ & $\begin{array}{c}\text { Temperature } \\
\text { in }{ }^{\circ} \mathrm{C}\end{array}$ & $\begin{array}{c}\text { Load } \\
(K N)\end{array}$ & $\begin{array}{c}\text { Ult } \\
\text { stress }\end{array}$ & $\begin{array}{c}\text { Yield } \\
\text { stress }\end{array}$ & $\begin{array}{c}\text { Max } \\
\text { Extn }\end{array}$ \\
\hline 1 & 27 & 66.8 & 0.58 & 0.462 & 1.63 \\
\hline 2 & 150 & 65.8 & 0.58 & 0.472 & 1.65 \\
\hline 3 & 350 & 65.1 & 0.58 & 0.449 & 1.44 \\
\hline 4 & 650 & 68.0 & 0.68 & 0.456 & 0.96 \\
\hline 5 & 950 & 79.1 & 0.79 & 0.479 & 0.21 \\
\hline
\end{tabular}

\section{Research and Methodology}

\subsection{Equipment}

- Universal Testing Machine

- Scanning Electron Microscope Electrical Furnace

- Electrical Furnace 


\section{International Journal of Science and Research (IJSR) \\ ISSN (Online): 2319-7064}

Index Copernicus Value (2015): 78.96 | Impact Factor (2015): 6.391

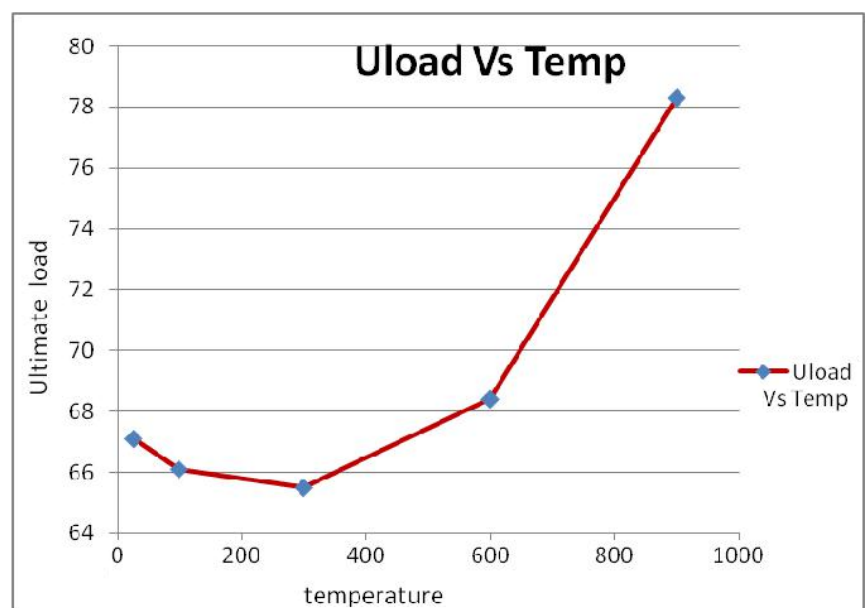

Figure 4.1: Unload vs Temp Curve

\subsection{Microscopic study (By SEM Analysis):}

Photos are clicked at the scale of 5 microns and 10microns after magnification

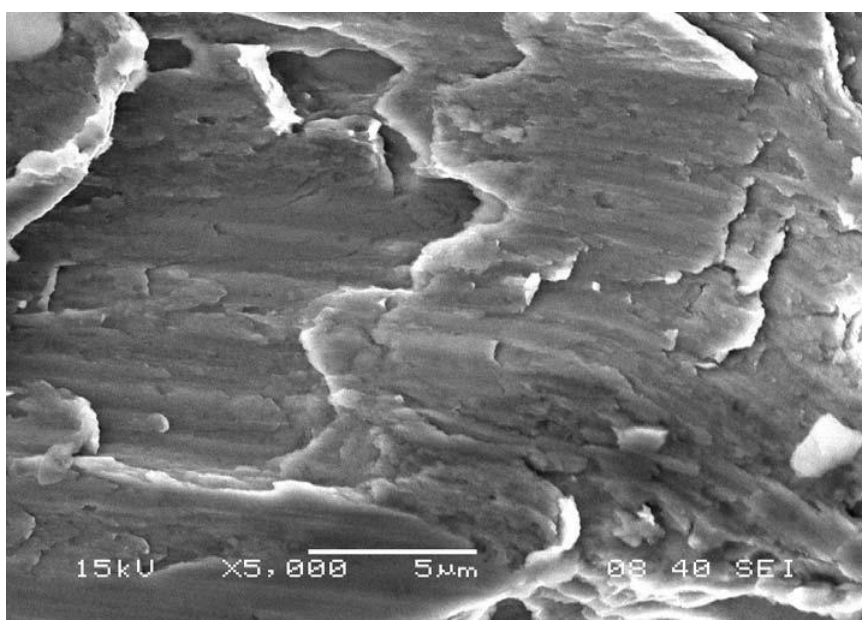

$150^{\circ} \mathrm{C}$ normally cooled 5 microns(magnified picture)

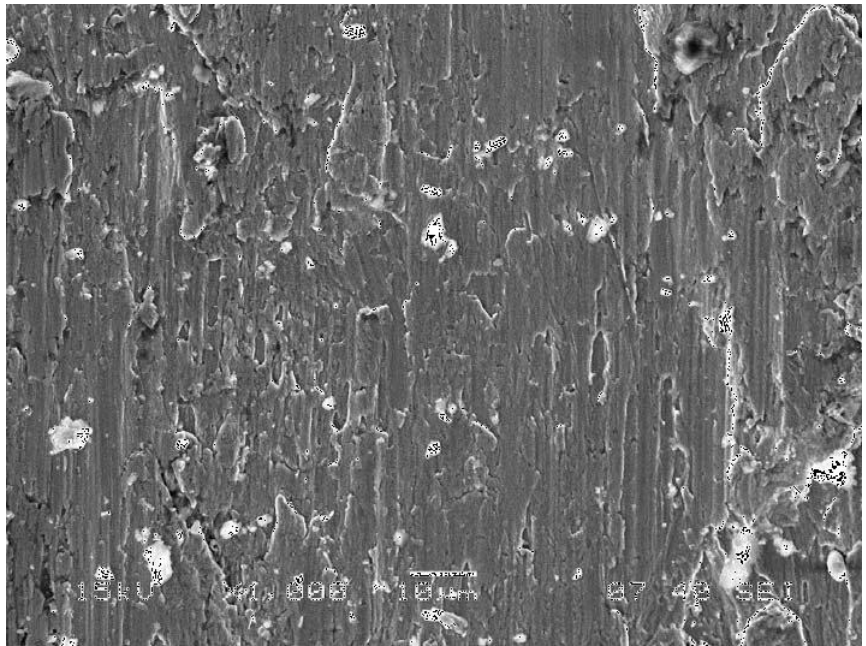

$150^{\circ} \mathrm{C}$ normally cooled 10 microns (magnified picture)

\section{Conclusion}

1) Behavior of reinforcement bars heated at various temperatures of $150^{\circ} \mathrm{C}, 350^{\circ} \mathrm{C}, 650^{\circ} \mathrm{C}, 950^{\circ} \mathrm{C}$, cooled rapidly by process quenching and also at normal cooling in the atmospheric temperature were studied and we observed that the reduction of ductility of bar when rapidly cooled after heating to high temperature to 950 ${ }^{\circ} \mathrm{C}$.

2) Observed the characteristic changes in the mechanical properties of the bars by Tensile strength testing using Universal Testing Machine shows that the increase in ultimate load and decrease in percentage elongation of the specimen which mean that there is significant decrease in ductility of the specimen.

3) Study of micro structure of the bars using Scanning Electron Microscope (SEM) also shows that the microstructure of highly heated specimens varies without varying the chemical composition which would have negative impact on the structure.

\section{Future Scope}

- By using these result we can modify the properties of reinforcement.

- We can make structure fire proof or thermal insulted.

- By using these result we can take prior action at the time of manufacturing of reinforcement to avoid more damage due to fire.

\section{References}

[1] Roberto Felicetti, DIS - Politecnico di Milano, P.za L. da Vinci 32, 20133 Milano,Italy 17 The drilling resistance test for the assessment of fire damaged concrete. April 2006

[2] M.A Riley,Msc. Possible new method for the assessment of fire-damaged structures. Sir william halcrow and patners- 1991

[3] Ian A.FLETCHER, Stephen WELCH, José L. TORERO, Richard O. CARVEL, Asif USMANI

[4] Wei-Ming,T.D.Lin,L.J.Powers-Couche. Microstructure of fire-damaged concrete.ACI

\section{Author Profile}

Mr. Ashish Juneja is a Student at department of Civil Engineering at R.N. College of Engineering (Panipat ). He is in his dissertation phase and his area of specialization is structural engineering.

Er. Rajinder Singh is an Assistant Professor at department of Civil Engineering at R.N. College of Engineering (Panipat ). He has guided a lots of students at B.tech and M.tech level. 